\title{
A New Genus and Species of the Langitanainae (Crustacea: Peracarida: Tanaidacea: Tanaidae) Bearing a New Genus and Species of Nicothoid Parasite (Crustacea: Copepoda: Siphonos- tomatoida: Nicothoidae) from the New Caledonia Slope
}

\author{
Roger N. Bamber and Geoffrey A. Boxshall \\ Department of Zoology, The Natural History Museum, \\ Cromwell Road, London SW7 5BD, United Kingdom \\ E-mail:R.Bamber@nhm.ac.uk (RNB)
}

(Received 25 July 2005; Accepted 22 February 2006)

\begin{abstract}
The Pacific collections by the MUSORSTOM campaigns of the Muséum national d'Histoire naturelle, Prais, over the last 20 years have included a number of Tanaidacea from waters of the New Caledonia region. The species described herein as Mekon solidomala, from 440 and $700 \mathrm{~m}$ depth, represents a new tanaid genus and species of the subfamily Langitanainae of the family Tanaidae. While displaying the ventrally fused pleonites four and five and the four-segmented antennule characteristic of the subfamily, it is distinct from the two previously known genera in having a non-flagelliform, foursegmented uropod, massive mandibles, and a large, subspherical carapace, the posterodorsal part of which overlaps the first and most of the second pereonite.

One tanaid paratype bore a copepod parasite representing a new genus and species of the family Nicothoidae, Arhizorhina mekonicola. This new genus appears most closely related to Rhizorhina in its extreme reduction of body segmentation and tagmosis, and in the total loss of limbs; however, it lacks the branching rootlet system that is diagnostic for Rhizorhina, and the stalk is configured differently.
\end{abstract}

Key Words: New Caledonia, Tanaidacea, Langitanainae, Copepoda, Nicothoidae, Mekon, Arhizorhina, parasite, new genera.

\section{Introduction}

Intensive sampling during the MUSORSTOM campaigns of the Museum national d'Histoire naturelle, Paris, over the last 20 years, largely from New Caledonia and its surroundings (see Richer de Forges 1990; Crosnier et al. 1997), has generated, inter alia, a collection of Western Pacific tanaidacean material. This material has kindly been made available to us for analysis. The tanaidacean fauna of the region of the Melanesian island systems is largely understudied.

A previous study (Bamber 2006) described four species of tanaidomorph from shallow waters $(\leq 20 \mathrm{~m})$ around New Caledonia. The present paper deals with a remarkable new tanaid collected during the BIOCAL cruise of the N.O. Jean Charcot 
off New Caledonia at depths between 440 and $700 \mathrm{~m}$ (the upper bathyal slope). The seven specimens, from two Warén dredge haul samples, represent a new species of a new genus of the subfamily Langitanainae of the family Tanaidae. One of the specimens bore a copepod parasite that represents a new genus and species of the family Nicothoidae. Both are described herein.

Type material has been lodged in the Muséum national d'Histoire naturelle, Paris (MNHN) and The Natural History Museum, London (BMNH). Morphological terminology of the tanaid is as in Bamber and Sheader (2005). The higher taxonomy of the Tanaidomorpha is based on Sieg (1980); that of the Copepoda is based on Boxshall and Halsey (2004).

\section{Systematics}

\section{Family Tanaidae Dana Genus Mekon gen. nov.}

Diagnosis. Female. Tanaid with relatively large, subspherical carapace over cephalon, dorsally covering first and part of second pereonite; six free pereonites, five pleonites free dorsally, anterior three of these bearing pleopods, posterior two without pleopods and fused ventrally (without suture). Antennules composed of four articles; antennae of seven articles; mandibles relatively massive, without palp, with lacinia mobilis on left mandible only; maxillule with palp. Pereopods without separate ischium; pereopods 1 to 3 with slender dactylus with claw; pereopods 4 to 6 with dactylus and claw fused into unguis; propodus of pereopod 6 with distal row of plumose spines. Uropods mounted ventrally on pleotelson, four-segmented.

Type species. Mekon solidomala gen. et sp. nov., by original designation.

Etymology. Named after the fictitious alien in the comic strip "Dan Dare", who also had a surprisingly large, round head; gender masculine.

Remarks. The uniramous antennules and uropods, and lack of a separate ischium on the pereopods, are all consistent features of the family Tanaidae. Sieg (1980) erected the subfamily Langitanainae to include two genera with four-articled antennules and with pleonites 4 and 5 lacking pleopods and not distinguished by a suture ventrally. Unlike Mekon gen. nov., both of these genera (Langitanais, with four species from the Antarctic and Subantarctic, and Arctotanais, with a single species from Arctic waters) have a flagelliform uropod of numerous segments, (nine to 11 and seven segments, respectively) and lack a row of specialized spines on the propodus of pereopod 6. Furthermore, the cephalon of both genera is relatively flattened dorsoventrally and does not override the first two pereonites.

The new genus appears closest to Langitanais, but is quite distinct owing to the features described above, inter alia.

Mekon solidomala sp. nov.

(Figs 1-4)

Material examined. Holotype: female (MNHN-Ta 902), BIOCAL, station DW51, New Caledonia, $23^{\circ} 05.27^{\prime} \mathrm{S} 167^{\circ} 44.95^{\prime} \mathrm{E}$ to $23^{\circ} 05.43^{\prime} \mathrm{S} 167^{\circ} 45.35^{\prime} \mathrm{E}, 700-680 \mathrm{~m}, 31$ 


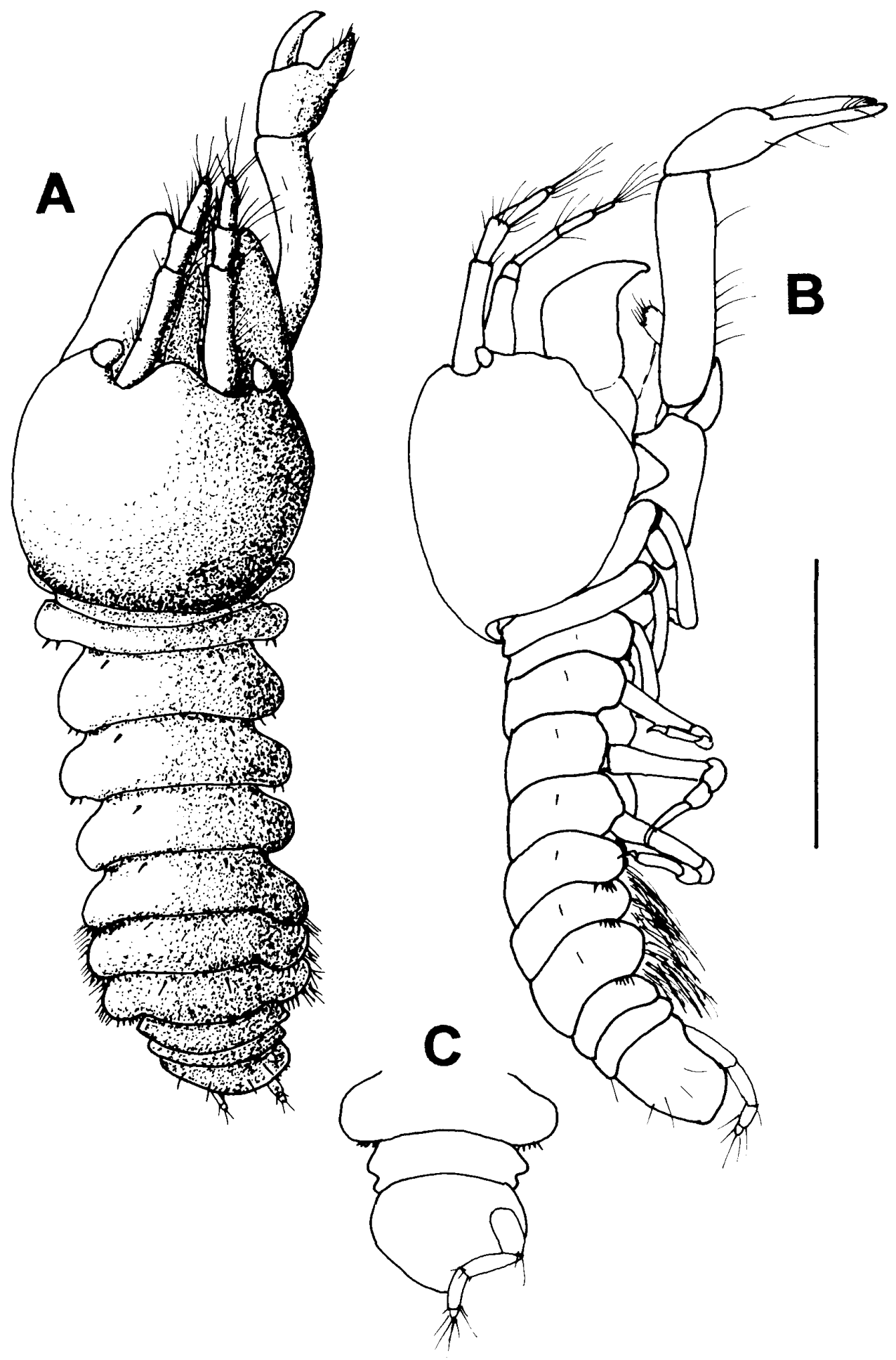

Fig. 1. Mekon solidomala gen. et sp. nov. A, B, Holotype, body, dorsal and lateral, respectively; C, paratype (MNHN-Ta 903), pleotelson and pleonites 4 and 5, ventral (only left uropod shown). Scale $=2 \mathrm{~mm}$. 
August 1985. Paratypes: figured female (MNHN-Ta 903) and 1 female (BMNH.2005.945), same data as holotype; 3 females (MNHN-Ta 904), and 1 female (MNHN-Ta 905) bearing a copepod parasite, BIOCAL, station DW44, New Caledonia, $22^{\circ} 47.35^{\prime} \mathrm{S} 167^{\circ} 14.50^{\prime} \mathrm{E}$ to $23^{\circ} 47.34^{\prime} \mathrm{S} 167^{\circ} 14.80^{\prime} \mathrm{E}, 440-450 \mathrm{~m}, 30$ August 1985.

Diagnosis. Monotypic, as for the generic diagnosis.

Description. Female. Body (Fig. 1A, B) robust, characterized by large, subspherical carapace constituting one-third length of body; length of holotype $5.45 \mathrm{~mm}$ (figured female $6.29 \mathrm{~mm}$; sympatric paratype female $4.67 \mathrm{~mm}$; paratypes from DW44 3.9 to $4.1 \mathrm{~mm}$ ). Cephalothorax subspherical, naked, 1.1 times as wide as long, with slight, rounded, downcurving rostrum; rear of carapace overlapping all of first and most of second pereonite. Eyelobes present, without pigment or ocelli.

Six free pereonites, all rounded laterally, with sparse lateral setae on each side and paired dorsolateral setae towards anterior end of at least posterior four pereonites. Pereonite 1 and anterior part of pereonite 2 not visible dorsally. Pereonites 1 to 3 subequal, about nine times as wide as long, together one-third as long as cephalon. Pereonites 4 to 6 subequal, 2.5 times as long as, and slightly narrower than, anterior pereonites, each about three times as wide as long. Pleon dorsally of five free pleonites; pleonites 1 to 3 of similar size and shape to posterior pereonites, with posterolateral rows of six or seven setae on each side; pleonites 4 and 5 half as long and two-thirds as wide as anterior pleonites, ventrally fused (Fig. 1C); pleopods on pleonites 1 to 3 only. Pleotelson ovoid, 1.2 times as wide as long, distally entire, with four to six dorsal setae.

Antennule (Fig. 2A) composed of four articles: proximal peduncle article 3.5 times as long as wide, with three proximal pinnate sensory setae, eight ventral setae, and two longer dorsodistal setae; second article one third as long as first, with three long dorsodistal setae; third article twice as long as second, with six subdistal setae; distal article (flagellum) very small, with two longer and two shorter distal setae and single aesthetasc.

Antenna (Fig. 2B) composed of seven articles: second article longest, with serrated edge on dorsoproximal apophysis; first, third, and sixth articles subequal, one-fifth of length of second article; fourth and fifth articles subequal, two-thirds of length of second; seventh very small. First and third articles naked, remainder with distal setae as figured.

Labrum (Fig. 2C) rounded, hood-like, naked. Left mandible (Fig. 2D) large, with robust lacinia mobilis with distal crenulation, strong pars incisive, and stout pars molaris with slender marginal teeth; right mandible (Fig. 2E) much as left mandible but without lacinia mobilis. Labium (Fig. 2F) with inner lobe finely setose on distal outer margin, outer lobe finely setose along inner and distal margins, labial palp present but not articulated, finely setose. Maxillule (Fig. 2G) with nine distal spines, inner pair fused; finely setose outer distal margin, and palp as long as endite with four simple distal setae. Maxilla (Fig. 2G) oval, simple; epignath not

Fig. 2. Mekon solidomala gen. et sp. nov., paratype (MNHN-Ta 903). A, Right antennule; B, right antenna; C, labrum, anterior (upper) and dorsal; D, left mandible, inner face; E, right mandible, inner face; F, labium, ventral; G, right maxillule with maxilla to right of centre, dorsal; H, right maxilliped, dorsal, with detail of distal endite seta; I, third right pleopod, anterior (most setae shown only by their bases). Scale $=1.0 \mathrm{~mm}$ for A-C, F-H; $1.3 \mathrm{~mm}$ for D, E; 0.4 $\mathrm{mm}$ for I. 
New tanaid with new copepod parasite

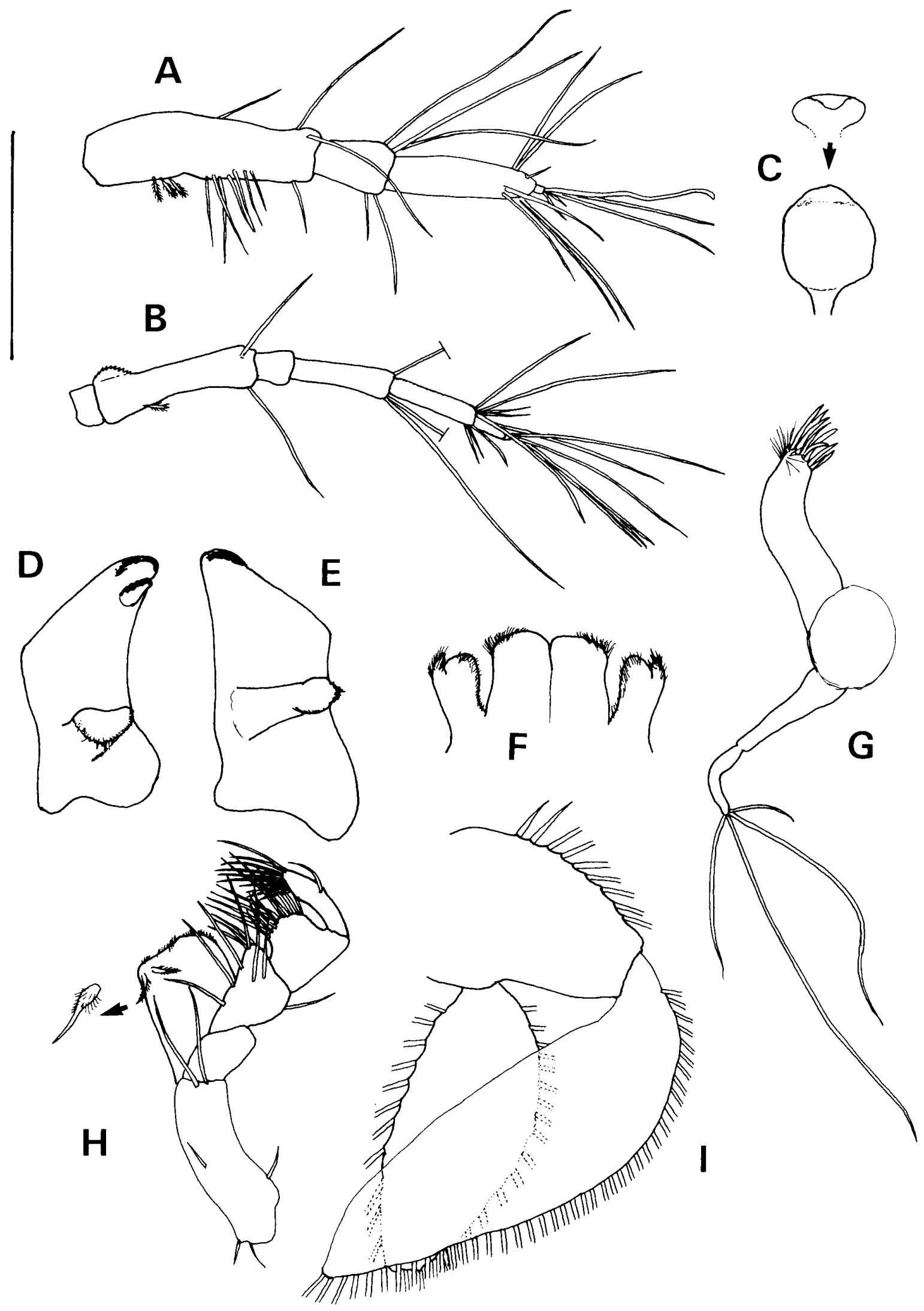


seen. Maxilliped (Fig. 2H) with endites rectangular, distally setose, each with two distal robust and basally plumose setae; maxilliped bases not fused, with two (right) or four (left) distal setae; first palp article naked; second article with four inner, two mesial, and one outer simple setae and with inner distal lobe bearing three smaller setae; third article with one row of nine setae and one row of three simple setae, all on inner marginal lobe; fourth article slender, with 11 distal and one outer setae.

Cheliped (Fig. 3A) stout, its basis subtriangular, naked; merus triangular, naked, articulating anaxially with basis and carpus; carpus 4.3 times as long as wide, with rows of dorsal and ventral marginal setae; chela 0.9 times as long as carpus; propodus with three ventral setae and midventral and paired distoventral setae on fixed finger; fingers of chela longer than palm (propodus); dactylus with crenulate cutting edge bearing fine setae.

Pereopod 1 (Fig. 3B) longer than others, setose as figured; coxa without apophysis; basis slender, seven times as long as wide; ischium not separate; merus onethird length of basis; carpus longer than merus; propodus 1.25 times as long as carpus; dactylus with proximal seta and distinct, slender claw, both together onethird as long as propodus. Pereopod 2 (Fig. 3C) with basis 4.7 times as long as wide, bearing three plumose sensory setae proximoventrally; merus 0.3 times as long as basis, with single short, toothed spine ventrodistally on each of anterior and posterior faces; carpus subequal in length to merus, with five laterodistal tooth-like spines on each side and paired ventrodistal spines; propodus 1.2 times as long as merus and carpus combined; setation, dactylus, and claw as pereopod 1. Pereopod 3 (Fig. 3D) similar to but shorter than pereopod 2.

Pereopod 4 (Fig. 3E) with basis stouter than above, three times as long as wide, with middorsal and ventrodistal pinnate sensory setae and three dorsal setae in distal half; merus twice as long as carpus and with paired ventrodistal tooth-like spines; ventral margin of carpus divided, with rows of eight tooth-like spines on each side; propodus as long as merus; dactylus and unguis fused into claw, curved, with lateral comb of three spines. Pereopod 5 (Fig. 3F) as pereopod 4, but with ventral rows of nine tooth-like spines on each side of carpus (Fig. 4A). Pereopod 6 (Fig. $3 \mathrm{G}$ ) as pereopod 5, but propodus with distal row of 11 unilaterally-plumose spines and two distal bilaterally plumose setae; comb on unguis composed of four spines (Fig. 4B).

All specimens without oostegites.

Pleopod (Fig. 2I) possessing basis with naked inner margin and nine outer plumose setae; exopod with 43 plumose setae along outer edge; endopod with 31 plumose setae around entire margin.

Uropod (Fig. 4C) uniramous, composed of four segments including basis, not flagelliform. Segments 2 and 3 longest, subequal, 3.5 times as long as wide; third segment with crown of subdistal setae; distal segment small, with numerous distal setae.

Male. Unknown.

Etymology. From the Latin solidus (massive), and mala (jawbone), referring to the large mandibles of this species; noun in apposition.

Remarks. Mekon solidomala sp. nov. has the four-articled antennule and the pleonite conformation typical of the subfamily Langitanainae, but is immediately distinguished from the two known genera of that subfamily by the subspherical 

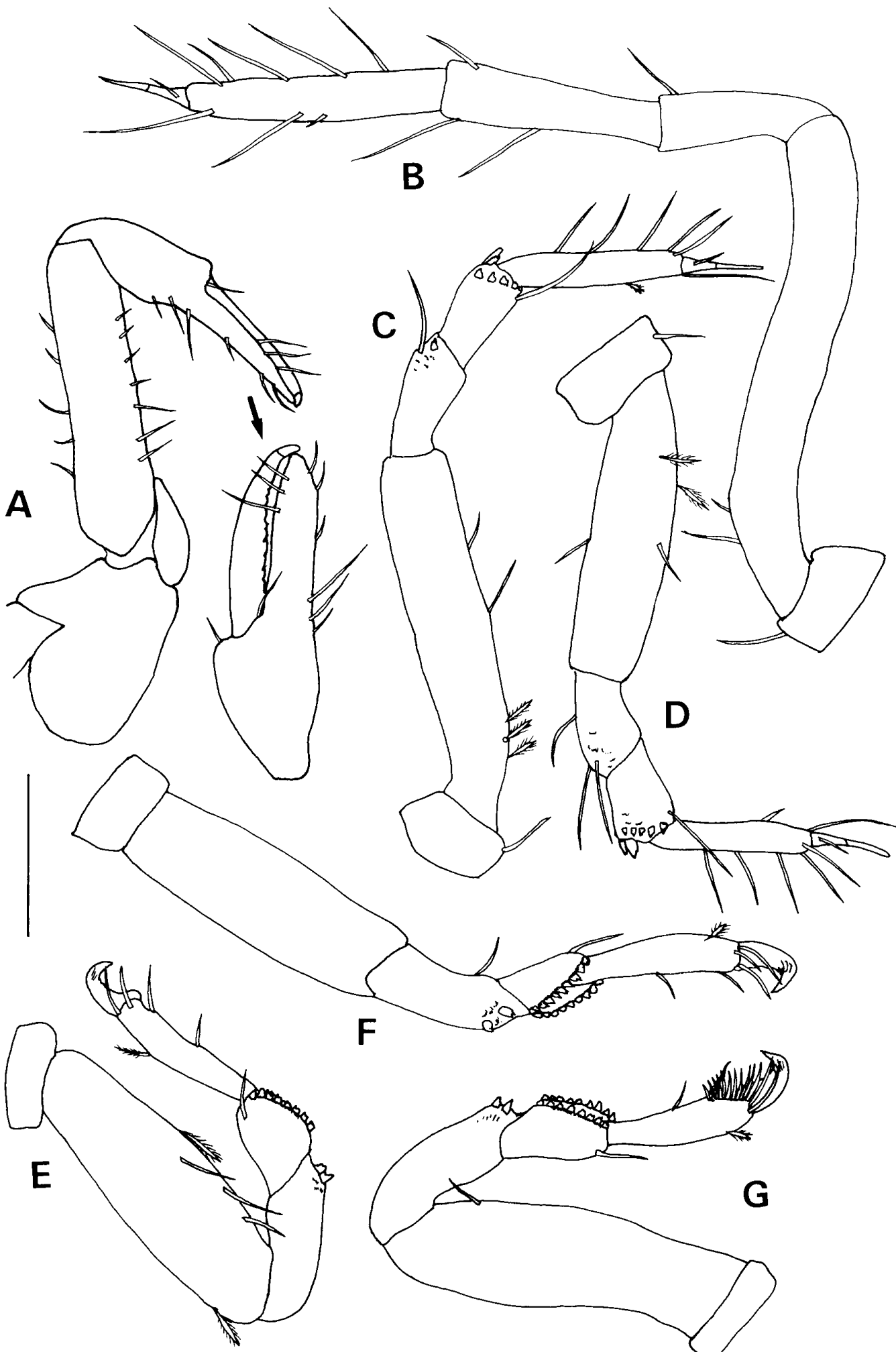

F

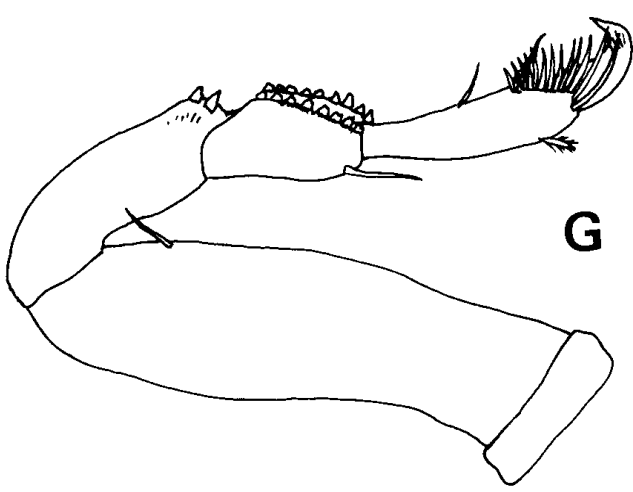

Fig. 3. Mekon solidomala gen. et sp. nov., paratype (MNHN-Ta 903). A, Right cheliped, with detail of chela; $\mathrm{B}-\mathrm{G}$, right pereopods 1 to 6 , respectively (B, D, E, and F posterior; $\mathrm{C}$ and $\mathrm{G}$ anterior). Scale $=1 \mathrm{~mm}$ for $\mathrm{A} ; 0.4 \mathrm{~mm}$ for $\mathrm{B}-\mathrm{G}$. 

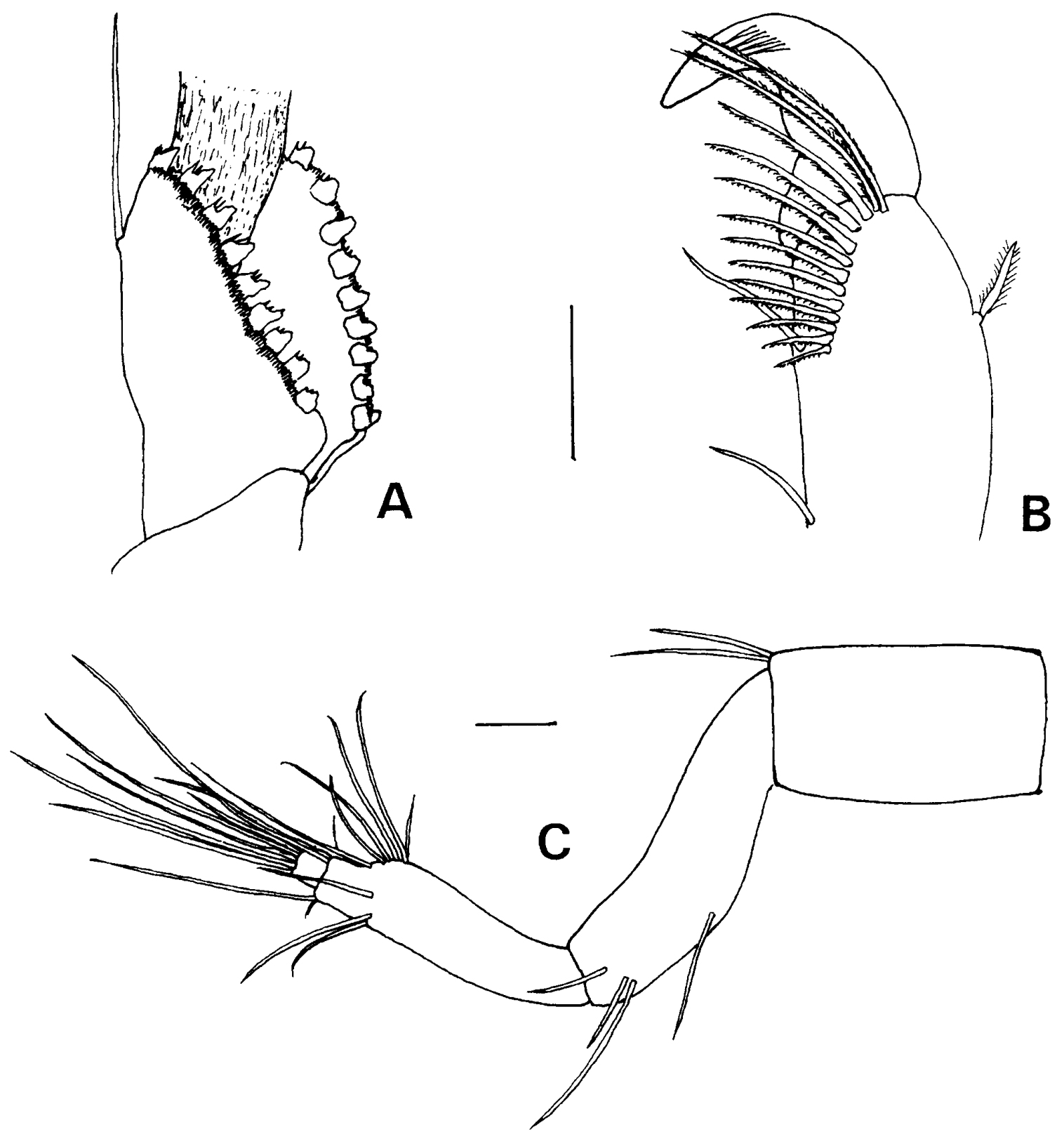

Fig. 4. Mekon solidomala gen. et sp. nov., paratype (MNHN-Ta 903). A, Carpus of pereopod 5 (propodal base shaded for distinction); B, propodus and unguis of pereopod 6; C, right uropod, ventral. Scales $=0.1 \mathrm{~mm}$.

carapace, the short uropods, the massive mandibles (which are conspicuous in dorsal and lateral view of the whole animal; Fig. 1A, B), and the presence of a distal row of denticulate spines on the propodus of pereopod 6 . Indeed, no other tanaid has the carapace conformation of the present species, including the posterior margin dorsally covering the first pereonite and much of the second one. 
Family Nicothoidae Dana

Genus Arhizorhina gen. nov.

Diagnosis. Female body swollen, slightly dorsoventrally flattened, wider than long; urosome completely incorporated into body. Attached to host by broad, sclerotized stalk arising anteriorly on ventral surface; stalk adhering to and penetrating host integument but terminating abruptly in funnel-like apex, lacking any system of rootlets. Paired genital openings apparently located posteriorly, either side of posterior midline. No vestige of any appendages retained in adult female. Male unknown. Parasitic on Tanaidacea.

Type species. Arhizorhina mekonicola gen. et sp. nov., by original designation.

Etymology. Prefix $A$, meaning negative (not), and Rhizorhina, the genus to which the new genus is closest; gender feminine.

Remarks. This enigmatic parasite is not a tantulocaridan since it lacks the tantulus larval head by which all ectoparasitic stages of tantulocaridans attach to their hosts. From its gross morphology and the host taxon utilised, it is most probably a nicothoid copepod, but this cannot be confirmed until new material (either males, larvae, or a female with a better developed genital system) is discovered.

There are currently 21 recognised genera of Nicothoidae (Boxshall and Halsey 2004; Ohtsuka et al. 2005). Eleven genera are characterised by a globular adult female in which the urosome is completely incorporated into the globular body, but at least some of the mouthparts are present in ten of these genera, with only the highly transformed Rhizorhina Hansen, 1892 sharing a total lack of mouthparts with the new genus. Rhizorhina attaches to its crustacean hosts by means of a short, narrow stalk, which penetrates the integument of the host and then divides repeatedly to form an extensive holdfast consisting of branching rootlets. The new genus lacks any branching system of rootlets and the stalk terminates abruptly in a funnel-like end. In addition, the nature of the stalk is quite different in the new genus. In Rhizorhina the stalk is relatively narrow (about $4 \%$ of the body width in Rhizorhina hystrix Boxshall and Harrison, 1988, for example) at the point of penetration through the host integument; in contrast, the stalk of the new genus is robust, comprising over $10 \%$ of the maximum body width. The stalk of our species also appears to have a central canal, a feature not reported for Rhizorhina species.

The new genus appears most closely related to Rhizorhina in its extreme reduction of body segmentation and tagmosis, and in the total loss of limbs; however, it lacks the branching rootlet system that is diagnostic for Rhizorhina and, indeed, the stalk is configured differently in the two genera. The new parasite cannot be placed in Rhizorhina without amending the generic diagnosis to the point of being meaningless. This combination of characters is unique within the family Nicothoidae and, despite the lack of the male, we propose to establish a new genus to house this obscure, highly transformed parasite. 
Arhizorhina mekonicola sp. nov.

(Fig. 5)

Material examined. Holotype: female (MNHN-Cp 2291), attached to sternum of fourth pereonite of a female specimen of the tanaid Mekon solidomala sp. nov. (see above), BIOCAL, station DW 44, New Caledonia, $22^{\circ} 47.35^{\prime} \mathrm{S} 167^{\circ} 14.50^{\prime} \mathrm{E}$ to $23^{\circ} 47.34^{\prime} \mathrm{S} 167^{\circ} 14.80^{\prime} \mathrm{E}, 440-450 \mathrm{~m}, 30$ August 1985 . Body length of host $4.02 \mathrm{~mm}$.

Diagnosis. Monotypic, as for generic diagnosis.

Description. Female. Body swollen, slightly dorsoventrally flattened, maximum width of $811 \mu \mathrm{m}$ greater than maximum length of $720 \mu \mathrm{m}$. Urosome completely incorporated into body; paired genital openings apparently located on either side of slightly convex mid part of posterior margin, but not well defined. Copepod attached to host by broad, sclerotized stalk region arising anteriorly on ventral surface. Stalk with discrete origin, about $250 \mu \mathrm{m}$ in length and between 87 and $105 \mu \mathrm{m}$ in diameter, apparently adhering to host integument around lesion in host surface, through which stalk enters, but terminating abruptly in funnel-like apex. Stalk with narrow central canal, but no distal system of rootlets. No vestige of any appendages retained in adult female. Slight swelling present on ventral surface anterior to origin of stalk. Body containing few large eggs (diameter approximately $190 \mu \mathrm{m}$ ) visible through body wall.

Male. Unknown.

Type host. Mekon solidomala gen. et sp. nov. (Tanaidacea).

Etymology. Named after the genus of the host and the Latin cola, meaning dweller; noun in apposition.

Remarks. This discovery constitutes only the second record of a copepod utilising a tanaidacean as host. The single nicothoid previously reported from a tanaidacean host is Rhizorhina tanaidaceae Gotto, 1984 from the apseudid Levia-
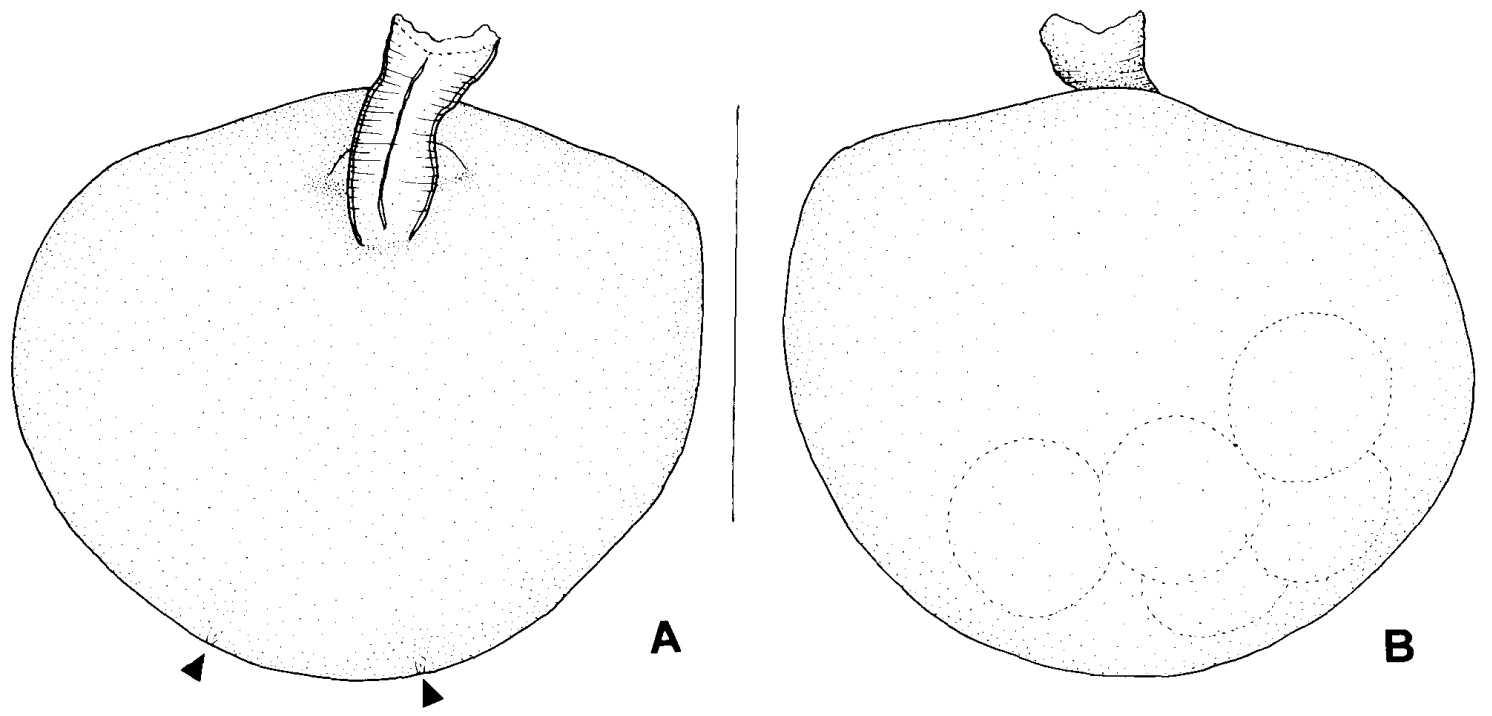

Fig. 5. Arhizorhina mekonicola gen. et sp. nov., holotype female. A, Body, ventral view, detached from host, showing well-defined origin of stalk (arrowheads indicating positions of putative genital apertures); B, same, dorsal view, with eggs visible through body wall. Scale $=0.5$ $\mathrm{mm}$. 
pseudes hanseni (Lang, 1968) taken at a depth of $2498 \mathrm{~m}$ in the North Atlantic off the coast of Ireland (Gotto 1984). Rhizorhina tanaidaceae is known from a single female, broken off from the host and therefore lacking its attachment structure. It has a short, narrow stalk which Gotto (1984) assumed represented the proximal part of a branching rootlet system that had been lost when the external body was detached from the host. The proportions of this stalk (short, narrow, and less than $4 \%$ of the body width) are in accord with other Rhizorhina species and support Gotto's assumption of missing rootlets. The new species occurs in shallower water, at a depth of 440 to $450 \mathrm{~m}$ off New Caledonia, and it utilises a host from a different family, the Tanaidae. The external body of the new species (width $811 \mu \mathrm{m} \times$ length $720 \mu \mathrm{m}$ ) is larger than that of $R$. tanaidaceae, which had a width of $594 \mu \mathrm{m}$ and a length of $500 \mu \mathrm{m}$, but the shape is similar. Rhizorhina comprises four species; in body length, the new species is intermediate between the smaller species $R$. tanaidaceae $(500 \mu \mathrm{m})$ and $R$. leptostracae Gotto, $1984(521 \mu \mathrm{m})$ and the larger species $R$. ampeliscae Hansen, $1892(960 \mu \mathrm{m})$ and $R$. serolis Green, $1959(2.0 \mathrm{~mm})$.

The holotype female contains five large eggs of about $190 \mu \mathrm{m}$ in diameter. They are relatively few in number and of a larger size than in Rhizorhina species, which typically produce many smaller eggs, as in Rhizorhina leptostracae with eggs averaging $83 \mu \mathrm{m}$ in diameter and not exceeding $125 \mu \mathrm{m}$ (Gotto 1984). Despite the large size of the eggs, the poorly developed genital openings may indicate that this female is not yet fully mature.

\section{Acknowledgements}

We are grateful to Dr Alain Crosnier and the Muséum national d'Histoire naturelle, Paris, for the opportunity to analyze their material and for the sampling data, and to Lisa Frewin and The Dan Dare Corporation Limited for their kind permission to use the name Mekon.

\section{References}

Bamber, R. N. 2006. Shallow water tanaidaceans (Crustacea: Peracarida: Tanaidacea) from New Caledonia and the Loyalty Islands. Zootaxa 1108: 1-21.

Bamber, R. N. and Sheader, M. 2005. Apseudomorph Tanaidacea (Crustacea: Malacostraca: Peracarida) from shallow waters off Sabah, Malaysia. Systematics and Biodiversity 2: 281-303.

Boxshall, G. A. and Halsey, S. H. 2004. An Introduction to Copepod Diversity. The Ray Society, London, $966 \mathrm{pp}$.

Crosnier, A., Richer de Forges, B. and Bouchet, P. 1997. Le campagne KARUBAR en Indonésie, au large des Îles Kai et Tanimbar. [In: Crosnier, A. and Bouchet, P. (Eds) Résultats des Campagnes MUSORSTOM Vol. 16]. Mémoires du Muséum National d'Histoire Naturelle, Paris 172: 9-26.

Gotto, R. V. 1984. Two new species of Rhizorhina (Copepoda: Siphonostomatoida) from leptostracan and tanaidacean hosts. Journal of Natural History 18: 811-817.

Ohtsuka, S., Boxshall, G. A. and Harada, S. 2005. New genus and species of nicothoid copepods (Crustacea: Copepoda: Siphonostomatoida) parasitic on the mysid Siriella okadai Ii 
from Japan. Systematic Parasitology 62: 65-81.

Richer de Forges, B. 1990. Les campagnes d'exploration de la faune bathyale dans le zone économique de la Nouvelle-Calédonie. [In: A. Crosnier (Ed.) Résultats des Campagnes MUSORSTOM Vol. 8]. Mémoires du Muséum National d'Histoire Naturelle, Paris (A) 145: $9-54$.

Sieg, J. 1980. Taxonomische Monographie der Tanaidae Dana 1849 (Crustacea: Tanaidacea). Abhandlungen der Senckenbergischen Naturforschenden Gesellschaft 537: 1-267. 